\title{
Comparative Analysis of Biodiesels from Calabash and Rubber Seeds Oils
}

\author{
J.O. Awulua, G.O. Ogbeh ${ }^{\mathrm{b}}$ and N.D. Asawa ${ }^{\mathrm{c}}$ \\ a,b \& c Department of Agricultural and Environmental Engineering, University of Agriculture, P.M.B. 2373 Makurdi, Nigeria
}

\begin{abstract}
Physicochemical properties of biodiesel from vegetable oils depend on the inherent properties of the oil-producing seeds. The purpose of this study is to investigate the physicochemical properties of biodiesels extracted from calabash and rubber seeds oils, as well as their combined oil mixtures with a view to ascertaining the most suitable for biodiesel production. Calabash and rubber seeds oils were separately extracted through the use of a mechanical press with periodic addition of water. Biodiesels were produced from each category of the oils by transesterification of the free fatty acid (FFA) with alcohol under the influence of a catalyst in batch process. The physicochemical properties of the biodiesels were investigated and comparatively analysed. The results obtained indicated an average of $1.40 \mathrm{wt} \%$ FFA for biodiesel produced from the purified calabash oil, which has a specific gravity of 0.920 , pH of 5.93 , flash point of $116^{\circ} \mathrm{C}$, fire point of $138{ }^{\circ} \mathrm{C}$, cloud point of $70^{\circ} \mathrm{C}$, pour point of $-4{ }^{\circ} \mathrm{C}$, moisture content of $0.82 \mathrm{wt} \%$ and specific heat capacity of $5301 \mathrm{~J} / \mathrm{kg} \mathrm{K}$. Conversely, the results obtained for biodiesel produced from the purified rubber oil showed an average of $33.66 \mathrm{wt} \% \mathrm{FFA}$, specific gravity of 0.885 , pH of 5.51, flash point of $145{ }^{\circ} \mathrm{C}$, fire point of $170{ }^{\circ} \mathrm{C}$, cloud point of $10{ }^{\circ} \mathrm{C}$, pour point of $4{ }^{\circ} \mathrm{C}$, moisture content of $1.30 \mathrm{wt} \%$ and specific heat capacity of $9317 \mathrm{~J} / \mathrm{kgK}$. However, results obtained for biodiesel produced from the combined oil mixtures indicated an average of 19.77 wt $\%$ FFA content, specific gravity of 0.904 , API gravity of $25.036, \mathrm{pH}$ value of 5.73 , flash point of $157{ }^{\circ} \mathrm{C}$, Fire point of $180{ }^{\circ} \mathrm{C}$, cloud point of $9{ }^{\circ} \mathrm{C}$, pour point of $5{ }^{\circ} \mathrm{C}$, moisture content of $0.93 \mathrm{wt} \%$ and specific heat capacity of $6051 \mathrm{~J} / \mathrm{kg} . \mathrm{K}$. Biodiesel produced from calabash seed oil is superior in quality to rubber seed oil, particularly in terms of its low FFA and moisture contents.
\end{abstract}

Keywords: Oils, Calabash, Rubber, Transesterification, Biodiesel.

Article History: Received April 16, 2015; Received in revised form May 19, 2015; Accepted June 20, 2015; Available online How to Cite This Article: Awulu, J.O., Ogbeh, G.O. and Asawa, N.D., (2015) Comparative analysis of biodiesel from calabash and rubber seed oil. Int. Journal of Renewable Energy Development, 4(2), 131-136. http://dx.doi.org/10.14710/ijred.4.2.131-136

\section{Introduction}

Fossil fuels, particularly petroleum, natural gas and coal have been the dominant sources of global energy supply for decades. But because these energy sources are non-renewables and the reserves are rapidly being depleted; couples with the incessant environmental problems such as air pollution and global warming that are associated with them, efforts are increasingly being made to harness sustainable energy from renewable resources. Renewable energy sources provide $25 \%$ of the total global energy, of which $14-16 \%$ is provided from biomass (Itodo 2007). Interestingly, alternative fuels, such as biodiesel, biohydrogen, biomethane and bioethanol are increasingly being generated from biomass in several places around the world. Biodiesel has taken the centre stage in several biomass and biofuel-based studies because it is produced from vegetable oils, which have the advantage of renewability (carbon neutral), biodegradability, safety, portability, non-toxicity, high heat content (about 88\% of diesel fuel), better lubricity, lower sulphur and aromatic contents. It is strongly recommended to be used in place of petroleum-based diesel in diesel engines. Unlike the other biofuels which require some form of modifications before they can be effectively utilized in their respective areas, biodiesel can be used in diesel engines with little or no modifications. Moreover, vegetable oils, the precursor of biodiesel are biodegradable because they have both lipid soluble and water soluble properties (Koh et al. 2011).

Edible vegetable oils such as sunflower, soyabean, rapeseed, corn, and canola have been used for biodiesel production. Non-edible vegetable oils like Jathropha curcas and others have also been found suitable. So far, more than $95 \%$ of the global biodiesel 
production comes from edible oil resources, particularly from the agricultural industry. This has led to the concern that the knock-on effect of this practice would be a global adverse food shortage (i.e. food versus fuel dispute) (Koh et al. 2011). But non-edible vegetable oils have been observed to be suitable for biodiesel production in developing countries because of food crises (Mustafa 2011). Moreover, the global production and distribution of vegetable oils resources are currently dependent on climate, soil and socio-economic factors. For instance, soyabean oil serves as the main resource for biodiesel production in the US, rapeseed and sunflower oils are currently being used in most EU countries, corn oil is being used in North America, palm oil is being used in some Asian countries and coconut oil is being used in the Philippines (Korbitz 1999).

Technically, biodiesel is produced by catalytic transesterification. Transesterification involves conversion of alcohol chemically in the presence of a catalyst to break its molecules to oil or fat. Usually, the reaction involves 1 mole of triglyceride (the primary constituent of vegetable oil) and 3 moles of alcohol (methanol) in the presence of sodium or potassium alkoxides as catalyst (Ma and Hanna 1999; Papadopoulos et al. 2010). Biodiesel obtained from this process is from the fatty acid methyl esters (FAME) of the vegetable oils. Biodiesel must be produced to strict industrial specification in order to ensure proper performance (Oseni et al. 2007). Although, efforts are being made to utilize $100 \%$ biodiesel in diesel engines, the current practice involves using blended biodiesel of different proportions with petroleum-based diesel in compression engines. Garpen and Tat, (2003) noted that biodiesel blends are most common in B20-B50. Economic feasibility studies showed that biodiesel obtained from non-edible oil is cheaper than that obtained from edible oil. But there exist certain problems like the high free fatty acid (FFA) content that are difficult to convert to biodiesel in non-edible oils (Papadopoulos et al. 2010).

Rubber fruits are barely edible, but contain viable seeds in which wasp is present. Rubber seeds which contain oil that can be exploited for biodiesel production are usually by-products of activities from rubber plants. Similarly, calabash which is notably cultivated in Nigeria is an annual climber, which grows to about $9 \mathrm{~m}$ at a very fast rate and produces seeds that are sweet in flavour and rich in oil, but possess certain characteristics which discourage people from feeding on it. Calabash develops fruits at 3 Months of age and each fruit contains at least 80-100 seeds depending on the size of the fruit (Schipper 2000).

The objective of this study is to compare the physicochemical properties of biodiesels produced from refined vegetable oil extracts of calabash and rubber seeds; with a view to ascertaining the most beneficial and suitable for biodiesel production and to compare their physicochemical properties with those of other nonedible vegetable oils.

\section{Materials and Methods}

Calabash and Rubber seeds oils (CSO and RSO) were extracted by using a mechanical press. Then, the extracted oils were separately refined in order to obtain the oils that are ideal for biodiesel production. The refined vegetable oils were transesterified with the aid of potassium hydroxide $(\mathrm{KOH})$ catalyst in order to produce biodiesel from each category of the oil. Thereafter, the physicochemical properties of each biodiesels, as well as that of their combined oil mixture were investigated. The results obtained were compared with those of other existing non-edible vegetable oil standards.

\subsection{Pretreatment of Raw Materials and Reagents Procurement}

The calabash seeds were procured from Mami market in Nassarawa State, Nigeria and rubber seeds were purchased from Cross River State. Equal volume of the seeds were measured and weighed separately. It was discovered that 4 litres of rubber seeds weighed $8.0 \mathrm{~kg}$ and the same volume of calabash seeds weighed $2.8 \mathrm{~kg}$. The seeds were de-shelled and sun-dried for 2 weeks. Thereafter, the seeds were crushed into fine size using a grinding machine and packaged in transparent sieving cloth. The following chemicals were procured: $2.25 \mathrm{~g}$ of Potassium Hydroxide (KOH), 0.1 litres of Ethanol, phenolphthalein, distilled water, and Sodium Hydroxide $(\mathrm{NaOH})$.

\subsection{Mechanical Extraction of Oils from Seeds}

The crushed seeds in the transparent cloth were separately mounted on a mechanical press. The mechanical press is cylindrical and is manually operated. Through a slow and continuous turning of its spiral screw, sufficient pressure was applied on the pressure area, where the crushed seed was placed for the extraction of the oil. Hot water was intermittently applied to facilitate the extraction of vegetable oil from the seeds. The extracted oil was collected in a bowl placed beneath the mechanical press, and then introduced into plastic rubbers. Adequate care was taken to allow for the extraction of the oil after repeated operations. The oils were separately refined by passing it through a $0.2 \mu \mathrm{m}$ filter and then dehydrated by cooking at $105{ }^{\circ} \mathrm{C}$ for $1 \frac{1}{2}$ hours with the aid of an electric stove to avoid hydrolysis of the triglycerides, and thereafter, introduced into new containers. Representative samples of each category of oil were obtained every ten minutes in order to investigate their physicochemical properties.

\subsection{Production of Biodiesels from the Oil extracts}

The batch method described by Selvan, (2007) was employed for the production of the biodiesels. The oils were purified using degumming method and subjected to transesterification. The oils were mixed at $60-90{ }^{\circ} \mathrm{C}$ with water and steamed for 30 minutes. The gumming residue was dehydrated and the oil was separated through the use of a centrifuge. Potassium 
ethanoxide was then prepared by reacting 0.28 litres of ethanol with $2.25 \mathrm{~g}$ Potassium hydroxide $(\mathrm{KOH})$ in a reactor. The heated oils were discharged into the reactor containing the ethanoxide. This mixture was introduced into the reactors and firmly closed. It was stored at a temperature above $71^{\circ} \mathrm{C}$ (boiling point of ethanol) for 75 minutes. Excess ethanol was allowed into the reactors to ensure total conversion of oils to esters. The content was then poured in a cylinder and covered and left to settle for 3 days. Two major products were formed: Glycerol which is denser and darker but lesser in quantity and biodiesel (esters) which appeared amber-yellow in colour, is less viscous but larger in quantity. The diesel which settled on top was separated from the glycerol with the use of stringe and stored in plastic cylindrical containers. Figure 1 is a schematic diagram of the experimental set up.

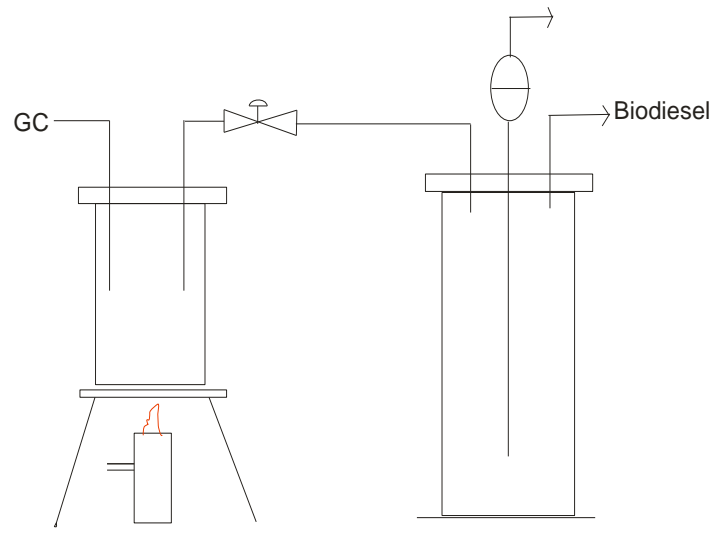

Figure 1. Experimental set up for the production of Biodiesels from RSO and CSO

\subsection{Analytical Methods for Oils and Biodiesels}

A preliminary moisture test was carried out by heating a little quantity of each oil sample in a container up to $110^{\circ} \mathrm{C}$ over a hot plate until a cracking sound was heard indicating the presence of water. A final test was carried out using an electric oven set between $105^{\circ} \mathrm{C}$ and $110^{\circ} \mathrm{C}$. The containers and their contents were weighed continually until a constant weight was obtained. The percentage water loss was determined for each sample.

The acid values of the extracted calabash and rubber seeds oils were evaluated by a standard titration procedure based on EN 14104. The acid value (expressed as mg $\mathrm{KOH}$ ) is a measure of the amount of $\mathrm{KOH}$ required to neutralize the FFA present in $1 \mathrm{~g}$ vegetable oil. About $2.0-2.5 \mathrm{~g}$ of each of the three categories of oils and the biodiesels was separately introduced into conical flasks and correctly labelled accordingly. $25 \mathrm{~mL}$ of diethyl ether was mixed with $25 \mathrm{~mL}$ ethanol and $1 \mathrm{~mL}$ phenolphthalein solution. Precisely $0.1 \mathrm{~mL} \mathrm{KOH}$ solution was titrated against this prepared mixture until a constant pink colour that persisted for 15 seconds was obtained. The acid value was determined by using equation 1 defined by David, (1970).

$$
\text { Acid value }=\frac{\text { Titre value }(\mathrm{ml}) \times 5.61}{\text { sample weight }}
$$

The free fatty acid content of each category of vegetable oil was determined in accordance to the international standard ISO 5509 for preparing methyl esters. This was done by using a HP 6890 series II Gas Chromatograph with flame ionization detector. It has a $30 \mathrm{~m}$ capillary column, a film thickness of 0.25 micron and an internal diameter of $0.32 \mathrm{~mm}$. The compositions of each category of the oils were analysed according to EN 14103.

Specific gravity bottles were weighed on an electronic weighing scale and their weights recorded. The bottles were filled with different samples and weighed. An equal volume of water was also weighed and its weight recorded as the specific gravity of each sample. The API's gravity of the samples was also determined through the use of equation 2 .

$$
\mathrm{API}^{\prime} \mathrm{S}=\frac{141.5}{\mathrm{SG}\left(15.5^{\circ} \mathrm{C}\right)}-131.5
$$

The kinematic viscosity was measured with a u-tube viscometer immersed in a constant temperature $\left(40{ }^{\circ} \mathrm{C}\right)$ as stipulated in the European norm EN ISO 3104. The pH values of the samples were determined through the use of a labtech digital $\mathrm{pH}$ meter as described by Sawyer and Kirk, (1991).

The specific heat capacity of each category of vegetable oil was measured thus: $2 \mathrm{ml}$ of each specimen was warmed in a beaker above room temperature (28 ${ }^{0} \mathrm{C}$ ) and the weights were recorded. The temperature of the oil was taken when it was $6{ }^{\circ} \mathrm{C}$ above room temperature. The beaker and its content were then placed in a copper calorimeter and the weight was recorded. Equation 3 was used to compute the specific heat capacity of the specimens.

$$
\left(M_{2} C+M_{1} C_{1}\right)\left(t_{1}-t_{2}\right)=M L+M C_{w}\left(t_{2}\right)
$$

\begin{tabular}{|c|c|c|c|}
\hline \multirow[t]{10}{*}{ Where } & $\mathrm{M}_{1}$ & $=$ & Mass of calorimeter $(\mathrm{kg})$ \\
\hline & $\mathrm{M}_{2}$ & $=$ & Mass of oil (kg) \\
\hline & $\mathrm{M}$ & $=$ & Mass of ice (kg) \\
\hline & $\mathrm{M}_{\mathrm{w}}$ & $=$ & Mass of Water $(\mathrm{kg})$ \\
\hline & $\mathrm{C}$ & $=$ & $\begin{array}{l}\text { specific heat capacity of oil (Jkg - } \\
\left.{ }^{1} \mathrm{~K}^{-1}\right)\end{array}$ \\
\hline & $\mathrm{C}_{\mathrm{w}}$ & $=$ & $\begin{array}{l}\text { specific heat capacity of water } \\
\left(\mathrm{Jkg}^{-1} \mathrm{~K}^{-1}\right)\end{array}$ \\
\hline & $\mathrm{C}_{1}$ & $=$ & $\begin{array}{l}\text { specific heat capacity of Copper } \\
\left(\mathrm{Jkg}^{-1} \mathrm{~K}^{-1}\right)\end{array}$ \\
\hline & $\mathrm{L}$ & $=$ & $\begin{array}{l}\text { Specific latent heat of fusion of } \\
\text { ice }\left(\mathrm{Jkg}^{-1}\right)\end{array}$ \\
\hline & $\mathrm{t}_{1}$ & $=$ & Initial oil temperature $(\mathrm{K})$ \\
\hline & $\mathrm{t}_{2}$ & $=$ & Final oil temperature $(\mathrm{K})$ \\
\hline
\end{tabular}

The cloud point, pour point, flash point, and fire point of the samples were determined as follows: 
Flash point and fire point: The oil samples were separately introduced into an aluminium container and heated using a Bunsen burner at the rate of $10{ }^{\circ} \mathrm{C}$ per minute. A thermometer was placed inside the oil and at every $5{ }^{\circ} \mathrm{C}$ increase in temperature; a small flame was passed over the oil surface until a flash appeared. The temperature at which the flash occurred was recorded respectively for each sample as their flash points. The samples were subjected to further heating beyond the flash points, until a small flame passed over the oil surface and continuously burned for 5 seconds. The temperatures at which this occurred for each sample were recorded as their respective fire points.

Cloud point and pour points: Each sample was introduced into separate test tubes; thermometers were inserted into them. They were thereafter firmly covered with the aid of corks and placed in a refrigerator. The samples were observed at intervals until they appeared cloudy; the temperature at which each sample became cloudy was recorded as its cloud point. The samples were further cooled and the test tubes containing the sample were bended at intervals to check for flow of oil until no flow of samples was observed. The temperatures of the samples at that point were recorded as their pour points.

\section{Results and Discussions}

\subsection{Physicochemical Properties of Oils from Calabash Seed}

The average free fatty acid content of the refined calabash oil sample was $22.44 \mathrm{wt} \%$. Its specific gravity was determined to be 61.10 . The density was determined to be $841 \mathrm{~kg} / \mathrm{m}^{3}$. The API gravity was 36.76 . The flash point was determined to be $310{ }^{\circ} \mathrm{C}$. The fire point was $335{ }^{\circ} \mathrm{C}$, the Cloud point $10{ }^{\circ} \mathrm{C}$ and pour point $40{ }^{\circ} \mathrm{C}$. The colour of the oil was observed to be yellow. Its moisture content was $2.30 \mathrm{wt} \%$, the specific heat capacity was determined to be $8895 \mathrm{~J} / \mathrm{kgK}$ and the $\mathrm{pH}$ was determined to be 5.61. Table 1 shows parameters of oils extracted from calabash and rubber seeds and Table 2 shows details of the physicochemical properties of oils from these seeds. Figure 2 shows the increasing yield of FFA contents of both RSO and CSO over the storage time for the experiment.

Tabel 1

Parameters of Oil from Rubber and Calabash Seeds

\begin{tabular}{lll}
\hline Quantity & Rubber & Calabash \\
\hline Average weight of seeds (kg) & 8.00 & 2.50 \\
Average weight of oil from seeds (kg) & 2.40 & 1.78 \\
Oil to seed ratio & 0.063 & 0.089 \\
\hline
\end{tabular}

\subsection{Physicochemical Properties of Oil from Rubber Seed}

The free fatty acid (FFA) content of the refined rubber seed oil was $94.20 \mathrm{wt} \%$. The specific gravity of the oil was determined to be 0.85 and the density was $850 \mathrm{~kg} / \mathrm{m}^{3}$. The APl degree was calculated as 34.97; the
$\mathrm{pH}$ was determined to be 5.3 ; the flash point was $225^{\circ} \mathrm{C}$; fire point was $246{ }^{\circ} \mathrm{C}$; cloud point was $18{ }^{\circ} \mathrm{C}$; and pour point $4{ }^{\circ} \mathrm{C}$, colour of oil was dark brown and has mild odour and its specific heat capacity was determined to be $12038 \mathrm{~J} / \mathrm{kgK}$. See table 2 for details.

Table 2

Summary of Physicochemical Analysis of RSO and CSO

\begin{tabular}{lcccccc}
\hline \multirow{2}{*}{ Property } & \multicolumn{3}{c}{ Unpurified Oil } & \multicolumn{3}{c}{ Purified Oil } \\
\cline { 2 - 7 } Colour & $\mathbf{X}_{\mathbf{1}}$ & $\mathbf{X}_{\mathbf{2}}$ & $\mathbf{X}_{\mathbf{3}}$ & $\mathbf{Y}_{\mathbf{1}}$ & $\mathbf{Y}_{\mathbf{2}}$ & $\mathbf{Y}_{\mathbf{3}}$ \\
\cline { 2 - 7 } Odour & Brown & Yellow & Brown & Brown & Yellow & Brown \\
$\gamma$ & Mild & Mild & Mild & Mild & Mild & Mild \\
$\rho\left(\mathrm{kg} / \mathrm{m}^{3}\right)$ & 0.8667 & 0.8512 & 0.9036 & 0.8500 & 0.8410 & 0.8772 \\
$\mathrm{API}$ & 866.7 & 851.2 & 803.6 & 850 & 841 & 897.2 \\
$\mathrm{pH}$ & 31.762 & 34.735 & 44.582 & 34.970 & 36.752 & 26.212 \\
$\mathrm{FFA}$ & 5.29 & 5.49 & 4.53 & 5.30 & 5.61 & 5.50 \\
$\mathrm{MC}(\%)$ & 97.00 & 22.44 & 53.29 & 94.20 & 1.96 & 53.29 \\
$\mathrm{SHC}(\mathrm{J} / \mathrm{kgK})$ & 2.00 & 4.19 & 1.70 & 1.95 & 2.30 & 1.00 \\
\hline
\end{tabular}

SHC=Specific heat capacity; $\gamma=$ Specific gravity

$X_{1}=$ Rubber oil, $X_{2}=$ Calabash, $X_{3}=$ Mixture of $X_{1}+X_{2}(1: 1)$

$Y_{1}=$ Rubber oil, $Y_{2}=$ Calabash, $Y_{3}=$ Mixture of $Y_{1}+Y_{2}(1: 1)$

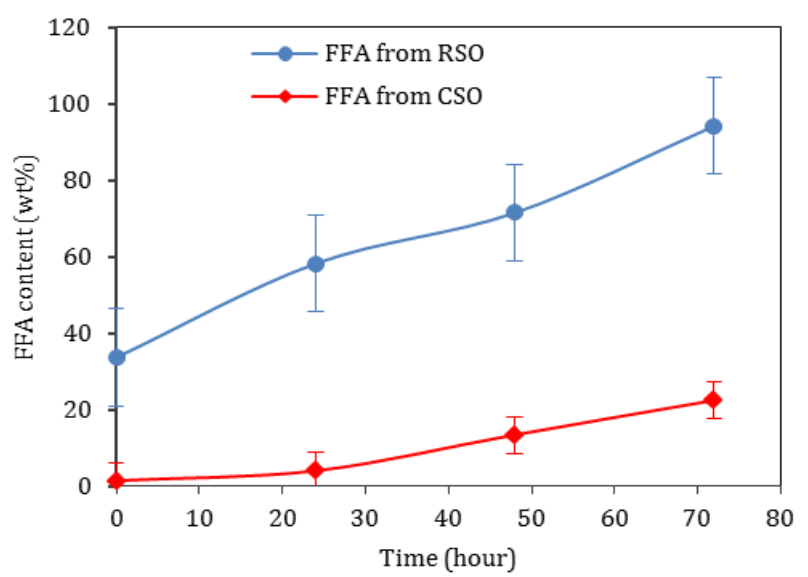

Figure 2. Increasing yield of FFA contents of RSO and CSO with storage time

The FFA contents of each category of the oils were compared with other non-edible vegetable oils as shown on Table 3.

\subsection{Physicochemical Properties of Biodiesel from Calabash Oil}

Qualitative analysis conducted on the biodiesel produced from calabash seed oil showed $1.40 \mathrm{wt} \%$ fatty acids content with specific gravity of 0.92 and density of $920 \mathrm{~kg} / \mathrm{m}^{3}$. The APl gravity was found to be 22.30 and it has a $\mathrm{pH}$ value 5.93. The flash point was $116{ }^{\circ} \mathrm{C}$; Fire point was $138{ }^{\circ} \mathrm{C}$, cloud and pour points of $70{ }^{\circ} \mathrm{C}$ and -4 ${ }^{0} \mathrm{C}$ were recorded respectively. The colour of the produced biodiesel was amber, which conformed to the observation of (Salvan, 2007).The glycerol formed at the bottom was cloudy yellow; moisture content was determined to be $0.82 \mathrm{wt} \%$. The specific heat capacity of the sample was determined to be $5301 \mathrm{~J} / \mathrm{kgK}$. 
Table 3

Free Fatty acid Compositions of Different Non-edible Vegetable Oils

\begin{tabular}{|c|c|c|c|c|c|}
\hline \multirow[t]{2}{*}{ Fatty acid } & \multirow[t]{2}{*}{ RSO } & \multirow[t]{2}{*}{ CSO } & \multicolumn{3}{|c|}{ (Koh and Mohd.Ghazi 2011) } \\
\hline & & & Jathropha & Sunflower & Karanja \\
\hline $\begin{array}{l}\text { Lauric } \\
\left(\mathrm{C}_{12} / 0\right) \\
\text { Myristic }\end{array}$ & - & - & - & 0.5 & - \\
\hline$\left(\mathrm{C}_{14} / 0\right)$ & - & - & - & 0.2 & - \\
\hline $\begin{array}{l}\text { Palmitic } \\
\left(\left(\mathrm{C}_{16} / 0\right)\right. \\
\text { Palmitoleic(C }\end{array}$ & 10.3 & 14.0 & 14.2 & 4.8 & 9.8 \\
\hline $\begin{array}{l}16 / 1) \\
\text { Stearic }\end{array}$ & - & 0.7 & 1.4 & 0.8 & - \\
\hline$\left(\mathrm{C}_{18} / 0\right)$ & 6.9 & 6.3 & 6.9 & 5.7 & 6.2 \\
\hline Oleic $\left(\mathrm{C}_{18} / 1\right)$ & 28.2 & 67.5 & 43.1 & 20.6 & 72.2 \\
\hline $\begin{array}{l}\text { Linoleic } \\
\left(\mathrm{C}_{18} / 2\right) \\
\text { Linoleic }\end{array}$ & 37.5 & 13.9 & 34.4 & 66.2 & 11.8 \\
\hline $\begin{array}{l}\left(\mathrm{C}_{18} / 3\right) \\
\text { Arachidic }\end{array}$ & 17.1 & 0.6 & - & - & 0.8 \\
\hline $\begin{array}{l}\left(\mathrm{C}_{20} / 0\right) \\
\text { Behenic }\end{array}$ & - & - & - & - & 0.4 \\
\hline $\begin{array}{l}\left(\mathrm{C}_{22} / 0\right) \\
\text { Saturates }\end{array}$ & - & - & - & - & - \\
\hline $\begin{array}{l}(\%) \\
\text { Unsaturates }\end{array}$ & 15.7 & 26.1 & 21.1 & 11.6 & 16 \\
\hline$(\%)$ & 84.3 & 73.9 & 78.9 & 88.4 & 84 \\
\hline
\end{tabular}

Viscosity for the biodiesel sample from calabash seed oil is as shown on Table 4. These results showed greater but near values as compared to the viscosity of the oil and conventional diesel. Viscosity-temperature coefficient on the biodiesel sample from calabash seed oil, were approximate that of the oil.

Table 4

Viscosity- Temperature Co-efficient on Biodiesel Samples

\begin{tabular}{llll}
\hline Samples & $12 \mathrm{rpm}$ & $30 \mathrm{rpm}$ & $60 \mathrm{rpm}$ \\
\hline $\mathrm{Z}_{1}$ & 0.078 & 0.134 & 0.079 \\
$\mathrm{Z}_{2}$ & 0.147 & 0.251 & 0.087 \\
$\mathrm{Z}_{3}$ & 0.0116 & 0.220 & 0.102 \\
\hline
\end{tabular}

\subsection{Physicochemical Properties of Biodiesel from Rubber oil}

From Table 5, the result from the qualitative analysis of biodiesel production from rubber seeds oil shows free fatty acid of $33.66 \%$ after 3 days of settling. This shows a drop of the fatty acid content to $60.54 \%$. The specific gravity of the oil from rubber seed was 0.885 . The density was then calculated to be $885 \mathrm{~kg} / \mathrm{m}^{3}$. The API degree was calculated to be 28.39. Flash point of the diesel was $145{ }^{\circ} \mathrm{C}$ and its fire point was $170{ }^{\circ} \mathrm{C}$. The cloud point was $10{ }^{\circ} \mathrm{C}$ and its pour point was $4{ }^{\circ} \mathrm{C}$. Consequently there was decrease in flash point (55\%); decrease in fire point (27.2\%); decrease in cloud point (80) and decrease in pour point (67\%).
Table 5

Summary of the Physicochemical Properties of Biodiesels Produced from Rubber and Calabash Oils

\begin{tabular}{lccc}
\hline Property & $\mathbf{Z}_{\mathbf{1}}$ & $\mathbf{Z}_{\mathbf{2}}$ & $\mathbf{Z}_{\mathbf{3}}$ \\
\hline Colour & Brown & Amber & Brown \\
Odour & Mild & Mild & Mild \\
$\gamma$ at $30^{\circ} \mathrm{C}$ & 0.89 & 0.92 & 0.90 \\
$\rho\left(\mathrm{kg} / \mathrm{m}^{3}\right)$ & 885 & 920 & 904 \\
$\mathrm{API}$ & 28.39 & 22.30 & 25.04 \\
$\mathrm{pH}$ & 5.51 & 5.93 & 5.73 \\
FFA $(w \mathrm{w} \%)$ & 33.66 & 1.40 & 19.77 \\
Flash point $\left({ }^{\circ} \mathrm{C}\right)$ & 145 & 116 & 157 \\
Fire point $\left({ }^{\circ} \mathrm{C}\right)$ & 170 & 138 & 180 \\
Cloud point $\left({ }^{\circ} \mathrm{C}\right)$ & 10 & 70 & 9 \\
Pour point $\left({ }^{\circ} \mathrm{C}\right)$ & 4 & -4 & 5 \\
MC $($ wt $\%)$ & 1.30 & 0.82 & 0.93 \\
SHC $(\mathrm{J} / \mathrm{kgK})$ & 9317 & 5301 & 6051 \\
\hline
\end{tabular}

SHC = Specific heat capacity, $\mathrm{Z}_{1}=$ Biodiesel from RSO, $\mathrm{Z}_{2}=$ Biodiesel from CSO, $\mathrm{Z}_{3}=$ Mixture of $\mathrm{Z}_{1}+\mathrm{Z}_{2}$

\subsection{Comparative analysis of rubber and calabash oil}

Oil ratio obtained from two vegetable oils (rubber and calabash) were obtained from gravimetric analysis of the two seeds. The ratio obtained shows that calabash seed has more oil (0.04) than rubber seed (0.03). By using mechanical extraction methods two products are obtained - the oil and the by-product (cake). The cake can be used as animal feed, if produced through modern extraction method such as solvent percolation (Bachman 2004). These ratios facilitate the evaluation of the quality of economic production and cumulatively indicate a high calabash seed oil yield, hence making amenable base-stock for production of biodiesel.

The result of qualitative analysis as presented, shows that calabash oil sample $\left(\mathrm{Y}_{2}\right)$ have lower free fatty acid content (1.96 wt\%) than that of rubber seed oil $\left(\mathrm{Y}_{1}\right)$ and for their mix $\left(\mathrm{Y}_{3}\right)$. See table 2 for details. Higher quantity of catalyst and oil ratios was required for rubber oil than calabash and their mix $\left(\mathrm{Y}_{3}\right)$. The free fatty acid content of both oils were found to be relatively closed to those of Jathropha curcas, sunflower and Karanja oils as found by Knothe et al. (2005) and Koh et al. (2011). See Table 3 for further details.

The specific gravity of the pure rubber oil, calabash oil and their mixture were determined to be $0.85,0.84$ and 0.88 respectively. The specific gravity of the biodiesel from the field stock (i.e. rubber and calabash) was determined to be $0.89,0.92$ and 0.90 respectively. Similarly the API gravity values of the Oils were 34.97 for pure rubber, 36.75 for pure calabash and 26.21 for the mixture. These shows that the calabash seed oil have a higher specific gravity and hence higher density than the rubber seed oils. The flash point, fire point, cloud point and pour point of the feedstock oils and their mixture reduce concurrently after production as compared to the biodiesels. The minimum flash point according to American standard is $100{ }^{\circ} \mathrm{C}$ (Knothe el al., 2005). The cloud and pour points of the oil were determined to be $10{ }^{\circ} \mathrm{C}$ and $4{ }^{\circ} \mathrm{C}$ respectively; while those of calabash were determined to be $7{ }^{\circ} \mathrm{C}$ and $-4{ }^{0} \mathrm{C}$ 
respectively. But the biodiesel from calabash oil shows better cloud and pour points result than biodiesel from rubber oil. Both diesels can be used conveniently in tropical regional areas like Nigeria (Itodo 2007).

The mixture content of pure oil sample (rubber and calabash) was determined to be $1.95 \mathrm{wt} \%$ and 2.30 $\mathrm{wt} \%$ respectively. Those of unpurified oil rubber and calabash were $2.0 \%$ and $4.1 \mathrm{wt} \%$. This shows that calabash contains higher moisture than rubber. With 1.95 wt\% moisture in rubber and $2.30 \mathrm{wt} \%$ moisture content in calabash, the biodiesels were produced with no saponification problems. But moisture content of 2.0 $\mathrm{wt} \%$ for rubber and $4.1 \mathrm{wt} \%$ for calabash, saponification occurs during transesterification of both oils. The biodiesel produce from rubber seed oil was quantitatively higher than that from calabash oil.

Although, the moisture contents of biodiesel from rubber seed oil and calabash seed oil are relatively high when compared to most other vegetable oils, biodiesel from calabash seed oil possessed lower moisture content than biodiesel from rubber seed oil. High water content hampers the conversions of triglycerides (Fernando et al. 2007) and slows down the settling of the glycerol (Roger et al. 2006).

The specific heat of the biodiesel (rubber, 93.17J/kgK) was observed to be higher than that of the petroleum diesel. Biodiesel from calabash has the worst heat capacity. That of rubber is more considerate than of calabash when compared to petroleum biodiesel.

\section{Conclusions}

Rubber seed and calabash seed have been transesterified to produce biodiesel successfully. Biodiesel from calabash seed oil gave clearer amber colour and requires less colour treatment when compared to biodiesel from rubber seed oil. Results of the physicochemical properties of biodiesel from calabash seeds oil have relatively high quality in terms of free fatty acid content, $\mathrm{pH}$, cloud point, pour point and specific gravity while biodiesel from rubber seed oil have higher quality in terms of fire point and specific heat capacity.

\section{References}

Bachman, J., (2004) Oil seed processing for small scale producer. Available @ http//www.oil.prcessing.com.

Fernando, B.D., (2007) Base-catalysed fast transesterification of soybean oil using ultrasonication. Energy and Fuel, 21: 1161-1164.

Gerpen, V.J. And Tat, M.E., (2003) Fuel Property Effect in Biodiesel. ASABE Paper No. 036034: American Society of Agricultural Engineering Annual Meeting, pp.70, Las Vagas, USA.

Itodo, I.N., (2007) Agricultural Energy Technology Concept. Department of Agricultural and Environmental Engineering, University of Agriculture, Makurdi.
Knothe, G., (2005) Dependence of biodiesel fuel properties on the structure if fatty acid alkyl esters. Fuel Processing Technology, 86(10): 1059-1070.

Korbitz, W., (1999) Biodiesel production in Europe and North America, an encouraging prospect. Journal of Renew Energy, Vol. 16, pp. 1078-1083.

Koh, M.Y., and Mohd.Ghazi, T.I., (2011) A review of biodiesel production from Jathropha curcas L. oil. J. Renewable and Sustainable Energy Reviews, 15:2240-2251.

Ma, F. And Hanna, M.A., (1999), Biodiesel Production: A Review. Bioresource Technology, pp. 70. Available @ 115.doi:10.1016/S0960-8524(99)00025-5.

Mustafa, B., (2011) Potential alternatives to edible oils for biodiesel production: A review of current work. Energy Conversion Management, 52:1479-92.

Oseni, M. I. and Kucha, E.I., (2007) Extraction and Evaluation of Wear Performance of Wild Melon Oil as an Industrial Lubricant. Journal of Research in Engineering, 4(1):6.

Papadopoulos, C.E., Lazaridou, A., Koutsoumba, A., Kokkinos, N., Christoforidis, A., and Nikolaou, N. (2010) Optimization of cotton seed biodiesel quality (critical properties) through modification of its FAME composition by highly selective homogenous hydrogenation. Bioresource Technology, 101:1812-1819.

Roger, A., (2006) Transesterification process to manufacture ethyl esters of rapeseed oil. Department of chemical Engineering, University of Idaho, pp.210, Moscow,

Sawyer, R. and Kirk, R.S., (1991) Pearson's composition and analysis of foods. John Wiley and Sons Inc. pp. 708, New York.

Schipper, R.R., (2000) African Indigenous Vegetables: An Overview of the Cultural Species. National Resources Institute/ACP-EU. Technical Centre for Agricultural and Rural Cooperation, Pp 12, Chathman, United Kingdom..

Selvan, P.V., (2007) Understanding the Process of Biodiesel Production. Department of Chemical Engineering, Universidade Federal do Rio Grande do Norte (UFRN), Brasil. 